\title{
Subjetividade e Complexidade Social: Contribuições ao Estudo da Depressão
}

SÔNIA REGINA DA CAL SEIXAS BARBOSA "

\section{RESUMO}

O presente artigo apresenta uma reflexão a partir de alguns dos resultados obtidos no projeto de pesquisa Qualidade de vida em sociedades complexas: a depressão entre trabalhadores da indústria petroquímica e pescadores artesanais. Vale ressaltar que a pesquisa é parte considerável de um caminho mais longo desenvolvido desde os anos 90. Através de intensa pesquisa de campo, analisou-se a qualidade de vida, através da observação dos estados depressivos presentes nos trabalhadores da indústria petroquímica (REPLAN, Paulínia, SP) e pescadores artesanais (Colônia Z 7 - Itaipu e Piratininga, Niterói, RJ), considerando que esses trabalhadores estão submetidos a intensas transformações socioambientais ocorridas em seus cotidianos e manifestam a depressão como expressão da subjetivação, no indivíduo, de uma intensa complexidade social.

Palavras-chave: Subjetividade; complexidade social; depressão; qualidade de vida.

Recebido em: 10/07/2006.

Aprovado em: 12/08/2006. 


\section{Introdução}

A análise das sociedades contemporâneas, a partir de um referencial das Ciências Sociais, tem-se mostrado um grande desafio quando se consideram as transformações socioambientais mais recentes e a diversidade e pluralidade das questões que as acompanham, permitindo considerar a presença de uma complexidade social cada vez mais crescente. Desta forma, a premissa que se estabelece é a necessidade de que os olhares devem ser ampliados para além de uma referência teórica exclusiva. Nesta perspectiva, a depressão pode ser considerada uma categoria analítica importante para a compreensão da subjetivação e das manifestações oriundas de um cotidiano complexo, que atua no indivíduo e exige que se levem em conta todos os aspectos que essa afirmativa pode conter: questões econômicas globais, mudanças na relação com a natureza, violência urbana, condições de empregabilidade, condições de moradia, relações pessoais e um crescente sentimento de impotência frente à realidade social. Enfim, um intenso mal-estar da civilização, que tem impedido a busca utópica da felicidade plena, prometida pelo iluminismo e capitalismo contemporâneo.

A pesquisa ${ }^{1}$ que origina estas reflexões parte de uma hipótese central que reside na afirmação de que as características desta época tão complexa como a que se vive têm um peso sobre a sociedade e, conseqüentemente, sobre o indivíduo, podendo ser analisadas em sua dimensão mais íntima - a subjetividade -, aliada a uma totalidade histórico-social interligada, abrangente e desconhecida no seu conjunto, que imprime novas abordagens políticas, espaciais, culturais, sociais e temporais para os diversos segmentos sociais, podendo alterar as condições subjetivas de existência para os indivíduos.

A reflexão sobre esse contexto social se ancorou historicamente numa referência empírica construída a partir de pesquisa realizada pela autora nos anos 90, constatada na existência de algo que era dito de forma metafórica e que pôde ser percebido durante uma entrevista com um médico do antigo Centro de Saúde Escola de Paulínia (São Paulo). Em seu depoimento, o médico explicitou que havia inúmeros pacientes que se apresentavam ao serviço expressando uma profunda tristeza, com idas constantes ao serviço ambulatorial por causa de nariz escorrendo, ou, como diagnosticado por ele, com doença da alma, não descrita em nenhum manual de medicina que se conheça (BARBOSA, 1990, p. 150).

Desta forma, o enfoque metodológico privilegiado nas pesquisas anteriores partiu dessa constatação inicial, apontada pelo profissional de saúde, 
e procurou analisar alguns aspectos das transformações socioambientais mais significativas e a realidade cotidiana de seus moradores, através da expressão difusa de sintomas manifestos no corpo, da queixa do sentir-se doente. E pela incapacidade de esses moradores evidenciarem suas necessidades e sofrimentos, via expressão verbal das questões fundamentais que enfrentavam no cotidiano, e que recebeu o nome metáforas corpóreas ${ }^{2}$ (BARBOSA, 1996).

Privilegiaram-se, desta forma, as trajetórias de repetição exaustiva de usuários de unidades básicas de saúde com sintomas mórbidos como dores, sensações corpóreas, insônia, além de tristeza e medo, refletindo em seus corpos uma dor do existir social, traduzido pela ausência de expressão verbal e política, e a impotência frente à construção de um projeto individual e social de vida. Tal trajetória, para os usuários desses serviços, não foi nada fácil e representou uma via crucis, percorrendo várias das especialidades oferecidas nos serviços e sendo, por fim, acolhida ${ }^{3}$ na área de saúde mental, com todo o significado que isso implica: alta medicalização, surtos psicóticos e internações hospitalares, bem como a perda de referências importantes para o viver.

Analisar essas expressões subjetivas tornou-se uma possibilidade que se instaura a partir da singularidade desses achados, procurando contribuir para repensar de forma abrangente a concepção de sociedades complexas e muito dos conceitos como o de qualidade de vida, identidade social e subjetividade. Concorre para ampliar o debate, porque o esforço que aqui se empreende resulta da perspectiva da constituição de um novo olhar ou, conceitualmente, de um olhar multi-referencial. Ressalta-se que olhar multi-referencial é aquele que considera a sociedade atual em suas formas complexas, diversas e plurais, e a partir dessa consideração reconhece a necessidade da multiplicidade de olhares e de linguagens para captar a realidade e a tradução do que de fato está procurando espaço de expressão (BARBOSA, 1998).

Tentar responder a essas perguntas coloca de imediato a premissa que se tem em mente de longa data e, vale ressaltar, abre um leque de possibilidades teóricas. E é em Lacan (1998), que se aposta para trazer à tona essa perspectiva. Numa citação exemplar ele nos diz que:

Freud assumiu a responsabilidade - ao contrário de Hesíodo, para quem as doenças enviadas por Zeus avançavam para os homens em silêncio - de nos mostrar que existem doenças que falam, e de nos fazer ouvir a verdade do que elas dizem, parece que essa verdade, à medida que sua relação com um 
momento da história e com uma crise das instituições nos aparece mais claramente, inspira um temor crescente nos praticantes que perpetuam sua técnica (LACAN, 1998, p. 216).

Se existem doenças que falam, como Freud afirmou e Lacan reforçou, a pergunta que aflora é: o que elas estão querendo dizer? O sofrimento psíquico que se manifesta nessa medida sob a forma da depressão propõe-se a dizer o quê sobre os indivíduos e suas condições sociais? Esse sofrimento psíquico, que em geral mescla uma série de elementos - tais como tristeza, apatia, busca da identidade, narcisismo - imputa imensas dificuldades para a clínica psiquiátrica, já que, como ressalta Roudinesco (2000), o indivíduo acometido pela depressão evidencia a descrença nas instituições, nas diferentes formas de organização social, nos sistemas de saúde e, por fim, até nas terapias.

Neste sentido, pode-se supor que os indivíduos, ao lidarem com a complexidade do mundo social, com sua subjetividade fragmentada, se vêem submetidos em seu cotidiano à dificuldade de lidar com o mesmo, já que as sociedades complexas podem patentear para todos, ou para um grande número de indivíduos, exclusão à participação política efetiva e dificuldades para compreender como operam em seu cotidiano os processos de globalização e aumento da violência em escala planetária, por exemplo.

Sentindo-se à margem dos processos sociais e econômicos, e não conseguindo verbalizar suas carências individuais, podem iniciar um processo de somatização dessa sua dor da alma, de sua tristeza mais profunda, seus problemas econômicos e sociais, através de expressões corpóreas (metáforas corpóreas), ou da depressão, ao invés de assumi-las sobretudo como um discurso político - político no sentido de organização e da possível viabilidade de transformação social. Pode-se considerar, desta forma, que não haverá distinção entre sociedades ditas tradicionais, como as constituídas pelos pescadores artesanais, e as não-tradicionais, como a dos trabalhadores de uma indústria petroquímica (FERREIRA, 2000; FERREIRA, CAMPOS, 2000), na medida em que as dificuldades se apresentam de forma semelhante para ambos os grupos sociais.

Várias foram as estratégias metodológicas desenvolvidas na pesquisa, levando-se em conta o conhecimento prévio das comunidades, através de contato anterior e da literatura produzida sobre as mesmas: ${ }^{4}$ ) observação da realidade cotidiana; 2) observação das instituições dos municípios como prefeituras, 
secretarias de Saúde, unidades básicas de saúde, unidades de saúde mental, subprefeituras e centros de apoio psicossocial (CAPS) das localidades; 3) entrevistas com profissionais da saúde, das unidades básicas de referência das comunidades (clínicos, psiquiatras, psicólogos e coordenadores de serviços) e outros envolvidos com a temática (psicanalistas, psiquiatras, analistas transpessoais e acupunturistas). Por último, entrevistas com alguns dos acometidos das duas comunidades. Neste artigo serão trabalhadas, exclusivamente, as contribuições teóricas sobre o estudo da depressão, alguns aspectos das regiões estudadas, aliados a resultados obtidos sobre os dois grupos de trabalhadores estudados.

\section{Um outro olhar sobre a depressão}

O sofrimento psíquico, a doença mental e mesmo a depressão são temas ricos e que têm sido objeto das Ciências Humanas, de algum tempo, já tratados pela autora em diversos momentos (BARBOSA, 2003 e 2004). Neste artigo serão privilegiadas as contribuições presentes na psicanálise e algumas outras abordagens que se relacionam à fronteira entre tal percepção e outros olhares, oriundos da experiência empírica que a pesquisa realizada procura oferecer, com o intuito de construir o novo olhar teórico que se almeja.

\section{A depressão na literatura psicanalítica}

Em 1917 Freud definiu melancolia, em contraposição ao luto, como sendo "um desânimo profundamente penoso e a cessação de interesse pelo mundo externo, a perda da capacidade de amar, a inibição de toda e qualquer atividade, e uma diminuição dos sentimentos de auto-estima a ponto de encontrar expressão em auto-recriminação, culminando numa expectativa delirante de punição" (FREUD [1917], 1999, p. 89-90). Segundo Delouya (2001), Freud parte de uma intuição inicial que obteve em 1895 sobre a melancolia: a articulação da mesma, com o estado esperado e conseqüentemente normal de luto, ou, em outras palavras, o elo da depressão melancólica com a nostalgia de algo perdido (DELOUYA, 2001, p. 29-36). Assim, na linguagem psicanalítica, a perda do objeto, a separação e o luto parecem constituir um eixo possível para o estudo da depressão.

Os estudos sobre a depressão, desta forma, sugerem várias abordagens, como se procura apontar. Seguindo a linha da psicanálise, tem-se em Winnicott 
(1999) uma afirmação significativa, quando ressalta que depressão traz consigo a hipocondria e a introspecção. Mesmo assim, como ressalta o autor, a depressão tem um valor (WINNICOTT, 1999, p. 59). E esse valor pode oferecer dois aspectos interessantes para seu entendimento, mesmo não esquecendo que um indivíduo deprimido, em estado severo, pode colocar em risco sua vida. Primeiro, não se pode desconsiderar que a depressão pertence à esfera da psicopatologia, e mesmo que seja severa e incapacitante, demonstra que para os indivíduos saudáveis é passageira, não importando quanto tempo dure uma crise. Segundo, depressão é um fenômeno comum e quase universal, relacionado com o luto, com a capacidade de sentir culpa e com o processo de maturação, pois sempre indica a força do ego e permite ao indivíduo sair da crise, tornando-o mais capacitado para a vida.

Fédida afirma, de forma enfática, que se existe uma doença do "vivente humano, ela seria por definição, a depressão" (FÉDIDA, 2002, p. 12), sobretudo porque sua forma de expressão se dá por uma sensação de imobilização, um impedimento de sentir os menores movimentos da vida, quer seja interna ou externa, na verdade uma total abolição de qualquer devaneio ou desejo, sobrepondo o que o autor descreve como se pensamentos, ações e linguagem fossem totalmente dominados por uma violência do vazio.

No entanto, esses aspectos acabam por se constituir num paradoxo, porque ao mesmo tempo em que se apresentam com significados importantes para evidenciar o sofrimento humano, também estão sendo banalizados e generalizados, já que, como afirma o autor, a psiquiatria não tem tempo e talvez interesse para observar e escutar o paciente, reduzindo a depressão a uma questão da realização de um preciso e competente diagnóstico e da prescrição de antidepressivos. O autor reconhece a importância desses procedimentos, mas chama a atenção no sentido de que a exclusividade que pode acontecer no tratamento exclui a possibilidade de reconhecimento do sujeito que sofre e, consequientemente, de seu aniquilamento psíquico.

Em outra obra, Fédida (1999) faz uma referência importante ao vazio que acompanha os estados depressivos. Esse vazio diz respeito à impossibilidade de se fazer ouvir, primeiro por si próprio e depois pelo outro. Mas também o vazio é uma metáfora, já que representa a hipótese do isolamento, da privação sensorial como medida de conservação de si, em estado de perigo. Na realidade o autor supõe, a partir das releituras de Freud, Lacan, Winnicott e Klein, aliadas a sua vasta experiência clínica, que o vazio presente de forma inexorável na 
depressão precisa ser objeto de escuta do analista, já que assume valor de um conceito pela freqüência com que está presente nas descrições dos pacientes deprimidos. Já que a psicanálise é o conhecimento da fala e de seus significantes, e não do corpo, como aponta Fédida, poderá representar a necessidade de um tempo de espera que dará sentido à existência - portanto, o vazio não é a morte, mas um ponto de apoio para a cura.

O que pode apontar a leitura psicanalítica? Pode indicar um caminho para se refletir sobre o significado da depressão nos dias atuais, já que tanto a melancolia como diversas outras formas de sofrimentos psíquicos estão sendo diagnosticadas e medicalizadas como depressão. Isso permite afirmar que, no século atual, a depressão assumiu o caráter de pandemia, muito provavelmente em função da sofisticação das possibilidades diagnósticas, do desenvolvimento das concepções bioquímicas e da gama de medicamentos ao dispor da medicina psiquiátrica atual.

\section{A depressão em outras abordagens}

Surgiram recentemente duas obras que dedicaram atenção especial à depressão. Alguns trechos bastante elucidativos podem ser pinçados de Solomon (2002):

Há duas modalidades de tratamento para a depressão: terapias da fala, que lidam com palavras, e terapias de intervenção física, que incluem os cuidados farmacológicos e o eletrochoque (TEC). Reconciliar a compreensão psicossocial com a compreensão psicofarmacológica da depressão é difícil, mas necessário. É extremamente perigoso e comum considerar um tratamento em detrimento do outro. A medicação e a terapia não deveriam competir por uma população limitada de depressivos: deviam ser terapias complementares que podem ser usadas juntas ou separadamente, dependendo da situação do paciente [...]. É moda os psiquiatras darem primeiro a causa da depressão (baixos níveis de serotonina ou antigos traumas são os mais populares) e depois, como se houvesse um vínculo lógico, a cura [...] (SOLOMON, 2002, p. 96).

É verdade que a medicação tem-nos libertado, mas todos devemos nos importar com as origens da doença [...]. O processo combinatório não é unicamente para as doenças mentais. $\mathrm{O}$ debate que coloca a medicação em oposição à terapia é ridículo (SOLOMON, 2002, p. 98). 
Wolpert (2003) é ainda mais enfático ao afirmar que existe uma corrente poderosa que afirma que a depressão depende de sua capacidade de aumentar a quantidade de neurotransmissores no cérebro, em especial a serotonina e a noradrenalina. $\mathrm{O}$ autor analisa a fundo os diversos tipos de medicamentos colocados à disposição da população em geral e seus efeitos, de formas diferenciadas para tratar da depressão. Destaca ainda que, apesar do desenvolvimento de medicamentos, seu tratamento é caro e demorado, pois as conclusões sobre suas ações e efeitos colaterais serão permitidas quando efetivamente o medicamento estiver disponível no mercado e sendo consumido por um significativo número de pessoas. A observação empírica e as várias entrevistas com profissionais de saúde indicaram que é extremamente perigoso não medicar um paciente com depressão severa, mas também é um risco medicálos sem ocorrer escuta ao sujeito deprimido.

Delouya (2001) foi brilhante ao trazer um questionamento que se aplica a esse debate ou pseudodebate, como salientam alguns. Na realidade, o psicanalista, ancorado nas leituras dos pioneiros da psicanálise e em sua experiência clínica, coloca a seguinte questão:

Podem os estudos da chamada pesquisa clínica, que estabelece correlações estatísticas entre as doenças afetivas - classificação de acordo com os respectivos diagnósticos - e o efeito da administração dos psicotrópicos, nos ensinar algo sobre o universo psíquico do doente? (DELOUYA, 2001, p. 27).

A crítica do autor recai na constatação de que essas pesquisas não têm relevância alguma para a investigação biológica, que procura evidenciar hipotéticos desvios dos mecanismos bioquímicos em ação, já que o tipo de abordagem não se vincula metodologicamente aos diagnósticos. Enfatiza que, para a psiquiatria, os procedimentos de acompanhamento dos pacientes estão em sua maioria calcados na objetividade de um protocolo onde o paciente é instigado a responder sobre suas condições de sono, alimentação, convívio familiar, atividades sexuais, dentre outras - ou seja, a frequiência ou tipo de manifestação de cada uma dessas categorias. No entanto, a psicanálise procura averiguar o sujeito, que é detentor de um saber próprio sobre cada uma dessas abordagens e, principalmente, de sua capacidade de abertura para cada uma dessas situações, bem como de seus fantasmas e a denominação do que se passa nele.

Assim, embora lembrando que a depressão tenha sido introduzida, em suas características nosográficas, no século XVIII, não se pode negar que 
assumiu hoje uma característica importante, em função de sua íntima ligação com os pilares da vida social (DIAS, 2003, p. 84), muito em função de que o sistema econômico atual se qualifica por uma economia livre, marcada por ritmos ciclotímicos. Essa oscilação vai marcar a posição dos sujeitos que estão na dependência das diferenças de oferta do mercado de trabalho e, nesse sentido, a perda de lugar é co-extensiva à estruturação da vida social, permitindo afirmar que, diante de tal conjuntura, a depressão é solidária do avanço da sociedade capitalista, com todas suas transformações e riscos impostos pela modernidade. Por fim, o sujeito na posição depressiva mobiliza a fuga, que é promovida pela acumulação do capital, qual seja, a experiência da queda como sinônimo da falência (DIAS, 2003).

Nessa perspectiva, vale o resgate às palavras do pai fundador da psicanálise no início do século XX. Na obra $O$ mal-estar da civilização, Freud já alertava:

O sofrimento nos ameaça a partir de três direções: de nosso próprio corpo, condenado à decadência e à dissolução, e que nem mesmo pode dispensar o sofrimento e a ansiedade como sinais de advertência; do mundo externo, que pode voltar-se contra nós com forças de destruição esmagadoras e impiedosas; e, finalmente, de nossos relacionamentos com outros homens. O sofrimento que provém desta última fonte talvez seja o mais penoso do que qualquer outro. Tendemos a encará-lo como uma espécie de acréscimo gratuito, embora ele não possa ser menos fatidicamente inevitável do que o sofrimento oriundo de outras fontes. (FREUD [1930], 1997, p. 25).

O importante a chamar atenção sobre essa afirmativa de Freud é que, mesmo considerando a perspectiva da abordagem psicanalítica, o autor já apontava para pensar o sofrimento do ponto de vista coletivo, destacando os fatores externos como causa, também, da constituição de sintomas do sofrimento humano. Assim, pensar as dores da alma sob essa dimensão requer considerar a questão da cultura, pois a vida psíquica do homem moderno está situada entre duas possibilidades: de um lado, os sintomas somáticos; de outro, as transformações dos desejos em imagens (KRISTEVA, 2002). Dentro dessa perspectiva, ela possui pouco espaço de expansão, podendo inibir-se e até fenecer, anulando por completo a possibilidade de expansão através do discurso. A expansão do discurso é que constrói o sujeito, e é esse sujeito que define um projeto social. 
Desta forma, a construção desse sujeito precisa considerar a cultura no qual está inserido, e vários autores têm tratado essa categoria como fundamental, seja através do seu caráter de proteção ou de construtor do sofrimento psíquico. Assim, Kleinman (1985) afirma, de forma categórica, que além dos fatores sociais e psicológicos, as questões culturais também exercem grande influência nos sintomas depressivos e no adoecimento.

Por sua vez, não só a consideração da cultura ajuda a evidenciar o sofrimento psíquico, mas os estudos interculturais podem contribuir sobremaneira para elucidá-los e colaborar para distinguir o que é normal do que é anormal ou seja, a forma como um transtorno é vivido, expresso e percebido por diferentes grupos sociais (KLEINMAN, 1985; WOLPERT, 2003). Esses estudos podem evidenciar a que tipo de risco os diferentes grupos sociais estão submetidos, considerando os fatores sociais que submetem os indivíduos a um grau de sofrimento, e como se expressam para lidar e superar suas dificuldades, enquanto indivíduo e enquanto sujeito social.

\section{Depressão: possibilidades de novas incursões teóricas}

É importante, no trato teórico da depressão enquanto categoria singular em sua construção na modernidade, destacar alguns pontos que permitam considerar seu caráter multi-referencial a partir das múltiplas possibilidades analíticas, evitando, desta forma, um reducionismo conceitual. As experiências empíricas e teóricas, baseadas em pesquisas realizadas pela autora (BARBOSA, 1990 e 1996) têm sido fundamentais, permitindo afirmar que se observava entre os pesquisados que, embora apresentassem sintomas eminentemente corpóreos - metáforas corpóreas - eram impulsionados às unidades básicas de saúde numa repetição cotidiana aos serviços, em suas diferentes especialidades, sendo por fim, exclusivamente, recebidos na área de Saúde Mental e diagnosticados como depressivos ou portadores de outros transtornos psíquicos. ${ }^{5}$

No entanto, em pesquisas mais recentes (BARBOSA, 2002; 2003; 2003a; 2004a; 2005, 2005a; 2006), a cisão entre corpo e mente, sintomas corpóreos, queixas físicas diversas e sofrimento psíquico, que essa categoria analítica poderia supor, deixou de ter significado teórico-metodológico significativo, sobretudo porque a abordagem teórica atual tem permitido significativos avanços na incorporação dessa dinâmica, como se poderá observar a seguir. 
A partir das contribuições de Fédida (2002), constatou-se que o caráter hipocondríaco ou psicossomático está presente na depressão. Esse aspecto é bastante significativo e expressivo dos intensos sintomas apresentados por esses pacientes e assim justificariam suas idas constantes aos serviços de saúde. Em exemplo clínico significativo, o autor chama atenção para o fato de que na fala de um paciente deprimido pode-se perceber sua preocupação com um único pensamento durante meses, de que "uma doença mortal está incubando sob a depressão" (FEDIDA, 2002, p. 12). Na leitura do autor, é apontado que "essa doença mortal ao qual se refere o paciente poderia estar sendo imaginada como um câncer", e surgiria de forma estrondosa, caso o estado depressivo desaparecesse de repente. Desta forma, é permitido supor que os sujeitos deprimidos exprimem muitas vezes pensamentos hipocondríacos e que tratam deliberadamente da morte, a morte por um órgão vital ter sido comprometido (FEDIDA, 2002, p. 12).

Assim, tanto quanto os aspectos exclusivamente mentais, depressivos, de derrota, ou sob a problemática hipocondríaca ou de sintomas físicos, podem estar as mesmas dificuldades e as agruras de lidar com a vida cotidiana, as transformações sociais e ambientais do mundo contemporâneo perpassados pela psique. O viver social e a dificuldade de contribuir para a construção de um projeto de sociedade podem ocasionar impasses para o indivíduo, que muitas vezes não sabe como responder a essa demanda. $\mathrm{O}$ ser humano cria mecanismos diferenciados para lidar e expressar sua angústia existencial e sua dor: seja ela uma sensação corpórea, um travamento da coluna cervical ou uma tristeza profunda que o deprimiu e o incapacitou para as atividades da vida cotidiana. ${ }^{6}$

Outro aspecto a ser mencionado diz respeito à consideração que deve ser levada em conta, com relação ao avanço dos diagnósticos dos estados depressivos e do sofrimento psíquico em geral na sociedade. Percebe-se hoje, cada vez mais, a presença e o temor que a incidência de depressão causa na sociedade contemporânea. Wolpert (2003, p. 15) destaca que o efeito que a depressão exerce sobre os serviços de atendimento de saúde tem sido enorme. Cita, para comprovar sua afirmação, que recente relatório - Global Burden of Disease - da Organização Mundial da Saúde, aponta que a depressão foi o quarto problema de saúde mais importante no mundo em desenvolvimento em 1990, responsável por 3\% da carga total de doença, e prevê que ela será o principal problema de saúde no mundo em desenvolvimento em 2020, com uma expectativa de ser responsável por $6 \%$ da carga total de doença. 
De acordo, ainda, com recente publicação sobre a depressão, advertese que 3\% dos norte-americanos (algo em torno de 19 milhões de pessoas) sofrem de depressão crônica, sendo que dois milhões deles são crianças, e a doença maníaco-depressiva (também conhecida como transtorno bipolar), acomete 2,3 milhões de pessoas, sendo considerada a segunda causa que mais vitimiza mulheres jovens e a terceira que mais vitimiza homens jovens. Nos países em desenvolvimento, a depressão responde pela maior parte do volume de doenças, calculada pelas mortes prematuras e de anos-vida saudáveis perdidos pela incapacidade, do que qualquer outra, exceto doenças cardíacas (SOLOMON, 2002, p. 24-25).

Essa suposição e os dados empíricos permitem afirmar que o sujeito na modernidade é fruto de uma série de referências, a partir das quais passa a construir seu discurso. O mundo atual promove uma transformação sem precedentes na subjetividade, e é nesse sentido que será possível entender melhor a sociedade contemporânea se a complexidade social atual for levada em conta. Com isso os olhares devem ser múltiplos, mas sedimentados na contribuição da sociologia para a auto-reflexão da sociedade e ajudando a entender outras formas possíveis de organização e relacionamentos sociais, que poderão ser viáveis para a coletividade e para a construção do sujeito contemporâneo (DOMINGUES, 2001).

Por isso é urgente ampliar o olhar e as abordagens multi-referenciais, para se captar o conflito entre a complexidade social e a vivência individual e coletiva. É evidente que não será possível pensar em problemas socioambientais de sociedades complexas e em suas soluções, caso não se reconheça a importância da articulação entre o indivíduo e a sociedade (BARBOSA, 1999). É esse o maior desafio que esta pesquisa se colocou.

Esse desafio aponta uma reflexão importante, no sentido de captar a multi-referencialidade que os dados empíricos apontam, bem como as possibilidades teóricas para analisá-los, pois que a articulação inevitável entre o indivíduo e a sociedade está presente e por isso faz necessário considerar o indivíduo como portador de uma psique, de um sentido e de uma referência. Isso contribui para compreender a sociedade através de significantes bastante definidos, como a fala, as expressões corporais e a expressão do sofrimento psíquico do sujeito. $\mathrm{O}$ estudo da depressão, assim, é compreendido nessa articulação. E mais que tudo, a depressão passa a ser fruto de uma sociedade fragmentada e desarticulada politicamente. 


\section{A experiência subjetiva da depressão e o cenário de sua expressão}

\section{A pesca e os pescadores: Itaipu, Piratininga, Niterói, Rio de Janeiro}

A colônia de pescadores de Itaipu, localizada no município de Niterói, Rio de Janeiro, tem sido objeto de estudo de alguns pesquisadores ao longo das últimas décadas. Embora tendo vários trabalhos como referência - LIMA (1997) e PESSANHA (2003), dentre os mais significativos -, o interesse fundamental nesta pesquisa é centrar atenção na dinâmica da qualidade de vida como fruto das transformações socioambientais mais importantes, observadas nas duas últimas décadas. Estas são aqui consideradas de forma relacionada ao sofrimento psíquico identificado nos pescadores que trabalham e habitam nessa região, considerando que o local da pesca é o local da vida, como tão bem destaca Duarte (1999, p. 31), quando afirma que "a referência à pesca preside a constituição das identidades sociais [...]. Viver da pesca é o índice geral com que se qualifica sua população e com que se designa a própria qualidade do bairro: um bairro de pesca".

A colônia de pescadores de Itaipu, atualmente denominada de Colônia Z-7, foi fundada em 1921, pela Capitania dos Portos. Abrange uma extensa área com 450 associados, incluindo as praias de Itaipu, Piratininga, Camboinhas, Itacoatiara, Itaipuaçu, Maricá e Ponta Negra. ${ }^{7}$

No início do século XX, como aponta Pessanha (2003), Itaipu registrava a presença de um número elevado de pescadores, que exerciam sua atividade com redes de emalhar e de arrasto, além de tarrafas e puçás na praia e na lagoa. Além disso, tem sido considerado um local tradicional de círculos de relações, seja com os mercados locais ou regionais, a administração pública ou com os diversos grupos e instituições que se apresentam ao local (LIMA, 1997).

Referir-se ao pescador de Itaipu significa falar sobre aqueles que pescam na praia de Itaipu, pertencentes à Colônia Z-7, incluindo os moradores de Itaipu, suas redondezas, e também Piratininga. Lima (1997) aponta como vantagens de ser pescador a relativa liberdade que a pesca possibilita, e como desvantagens à não-filiação ao INSS e a incerteza da remuneração, pois "o que ganha num mês come no outro" (LIMA, 1997, p. 66). O autor também observou que muitos dos filhos de pescadores não se voltavam para as atividades paternas (atualmente encontrou-se uma situação diferenciada, o que de certa forma possibilitou uma análise sobre identidade e depressão entre alguns jovens pesquisados), e também que as funções masculinas se vinculavam à participação 
nas atividades da pescaria, e como atividades femininas, além dos afazeres domésticos, a feitura de redes, atividade que vem decaindo, já que se encontrou na pesquisa de campo atual uma única mulher que se identificava como fazedeira de rede.

De acordo com as entrevistas realizadas entre os pescadores que são moradores da região da colônia, os principais problemas apontados são: a) ocupações irregulares, fazendo-se presente, de acordo com o presidente da colônia, a necessidade de regularizar a situação das casas dos pescadores, através de reintegração de posse regular; b) 32 bares na orla (na época da pesquisa de campo), entre as casas dos moradores e a extensão de praia; c) em função disso há inúmeros problemas como detritos na areia, sujeira, lixo e areia contaminada; d) limpeza da Baía de Guanabara: em entrevista foi destacado que a draga está deixando o lixo na praia, para baratear os custos da operação, embora devesse deixá-lo a 15 milhas da Ilha Rasa, suficientemente distante da praia (Projeto Despoluição da Baía de Guanabara). A questão do lixo será apontada em outras entrevistas como um dos sérios problemas da área, e conseqüentemente como empecilho à boa qualidade de vida da região. ${ }^{8}$

\section{A vida da pesca e a subjetividade}

No caso específico dos moradores da Colônia Z-7, observou-se, através dos primeiros contatos, a existência de um número significativo de pescadores, ou suas esposas e filhos, que narravam a presença de diagnóstico recente de depressão, obtido através dos serviços de saúde pública da região. Muitos deles se prontificaram a narrar suas histórias de vida, e relatar o momento em que obtiveram esse diagnóstico, a partir de um sofrimento anterior, em que a exacerbação de dores e sensações corpóreas, aliadas à angústia e dificuldade de concentração ao trabalho, foram a tônica durante um longo período de suas existências.

Vale lembrar que na pesquisa de campo esse número significativo corresponde à existência de $9 \%$ de moradores adultos com diagnóstico de depressão grave ${ }^{9}$ e outros $25 \%$ com diagnóstico médico de sintomas relacionados a estresse (insônia, elevação de pressão arterial, dentre os mais comuns). Os acometidos são em sua maioria jovens adultos (faixa etária de 22 a 30 anos) e adultos (acima de 40 anos), sendo dois homens e cinco mulheres. Os homens são pescadores e as mulheres distribuem-se em atividades como donas-de- 
casa, cabeleireiras e estudantes. Foram também realizadas entrevistas com os profissionais de saúde da Policlínica de Saúde de Engenho do Mato, Niterói, Rio de Janeiro, e entrevista com a psicóloga que atua no serviço. Para a região de abrangência do serviço (20.000 consultas/mês), 500 pacientes são atendidos pela área de Saúde Mental e, destes, 80\% (400 pacientes) têm diagnóstico de depressão e síndrome do pânico, ${ }^{10}$ estando em acompanhamento medicamentoso e terapêutico no serviço. A maioria das queixas é: dor de cabeça; hipertensão, considerada sempre a primeira queixa do paciente quando procura o serviço. ${ }^{11}$

A percepção dos estados depressivos diagnosticados por parte dos acometidos, obtidos através das entrevistas qualitativas, mostrou uma riqueza de percepções e impressões sobre seu próprio sofrimento. Houve, da parte dos entrevistados que aceitaram participar da pesquisa, muita determinação em contar sua história. O que chamou atenção logo no início foi a discussão sobre identidade social: "Vivo buscando a minha identidade: quem sou?" (depoimento à autora).

Essa busca essencial do ser humano está presente em todas as sociedades, sejam elas contemporâneas ou tradicionais. No entanto, no dizer de Hall (2000), as sociedades modernas são aquelas definidas por estarem em constante mudança, de forma rápida e permanente. Apesar disso, atualmente as chamadas sociedades tradicionais também estão passando por mudanças significativas e constantes. O exemplo da história de vida dos entrevistados nos permitiu refletir sobre isso. Algumas falas auxiliam nessa reflexão, principalmente se levarmos em conta a identidade propiciada pela tradição e os valores que são mantidos através da dinâmica da organização do trabalho:

Quando eu era criança não imaginava ser pescador, pois toda vez que eu via um avião eu dizia que queria ser piloto [...]. Mas como meu pai era pescador e todos os meus tios, meu avô também e eu estava aprendendo com ele a pescar, mas quando ele morreu (pai era pescador e morreu afogado quando ele tinha dez anos), as pessoas da colônia tiveram pouca paciência comigo e não aprendi mais (depoimento à autora).

Eu nunca tive vontade de ser pescador, mas meu pai e meu irmão mais velho são pescadores e assim não deu para sair da rotina da pesca (depoimento à autora).

Fica evidente, nos dois depoimentos, que não havia uma identificação com a pesca. No discurso dos acometidos percebe-se uma clara interferência 
na escolha profissional. Em todos os discursos estava presente a não-vontade de ser pescador. Ambos foram lançados a uma identidade que não necessariamente lhes pertencia, e assim a busca permanece, através de uma crise existencial profunda, que acabou por desembocar na depressão diagnosticada.

Esse aspecto é claro na referência que Hall faz a Giddens, onde o passado é venerado e os símbolos são valorizados porque são capazes de conter e perpetuar a experiência de gerações, no caso específico da atividade da pesca artesanal. Nesse sentido, a pesca artesanal permite, com o tempo e o espaço inseridos nessa atividade, a continuidade do passado. Nos depoimentos ficou claro o estigma que se acabou criando em torno deles, em função de terem que se afastar da atividade da pesca nos momentos de crise. Passaram a ser considerados pela maior parte da comunidade como preguiçosos e pouco afeitos ao trabalho pesado. Obviamente não se pode afirmar que os estados depressivos dos entrevistados tenham sido ocasionados pela não-adequação ao mundo tradicional e esperado pela comunidade ao trabalho da pesca, mas nas afirmações seqüentes há mais pistas para refletir sobre isso: "Tenho síndrome de pânico há um ano e três meses" (depoimento à autora). Ou: "Sei que tenho um problema espiritual e sentia sensações estranhas no corpo e depressão e inseguranças e pensamentos fixos, pânico, e com muitos medos" (depoimento à autora).

Ao afirmarem e nomearem seus problemas de saúde, é possível pensar na construção de uma (outra) identidade. Em pesquisas anteriores, pudemos constatar as mesmas afirmações, que só provocaram melhora na qualidade de vida quando os acometidos passaram a participar de grupos terapêuticos, onde perceberam que várias outras pessoas possuíam o mesmo sofrimento (BARBOSA, 1996).

Pode-se perceber nas entrevistas que esses acometidos possuem discursos bastante coerentes, articulados e significativos. Um deles chamou atenção da pesquisadora ao declarar que pesquisou tudo sobre a sua doença através da Internet - fato comprovado pela maneira como se expressava e apresentava várias estatísticas mundiais sobre depressão e síndrome do pânico. Em outro depoimento, foi possível observar o interesse por artes plásticas e desenho, e ele apresentou alguns desenhos que fez em determinados momentos. Esse caso específico declarou sua intenção de trabalhar com crianças e adolescentes da comunidade, ministrando cursos de desenho e pintura.

Toda a riqueza dos depoimentos e das histórias contadas à pesquisadora não se esgota aqui, mas permite associar a percepção que os entrevistados 
possuem de suas vidas na comunidade à depressão e às sociedades complexas. Em seus depoimentos ficou preservado o reconhecimento dos principais problemas da comunidade: lixo; pouca participação política; excesso de turistas, provocando problemas com pessoas que são estranhas à comunidade, dentre alguns dos observados. Nesse sentido, mesmo reconhecendo a importância das questões íntimas e pessoais, que não cabe aqui comentar, é notório que os problemas apontados dizem respeito a suas vidas de forma intensa e evidenciam os limites da comunidade, tanto geográficos quanto sociais e políticos, para lidar com suas inúmeras questões socioambientais.

\section{O pólo petroquímico e seus trabalhadores: Paulínia, São Paulo}

A história do município de Paulínia, considerado de pequeno porte no interior paulista, pertencente à Região Metropolitana de Campinas - com uma área total de $144 \mathrm{~km}^{2}$, sendo $88 \mathrm{~km}^{2}$ de área urbana e $56 \mathrm{~km}^{2}$ de área rural não difere muito de muitos outros pólos petroquímicos do Brasil, como Cubatão, Camaçari e Duque de Caxias. Atrai população para seu parque industrial até hoje, mas uma parcela significativa desses trabalhadores não é absorvida pelas grandes indústrias do pólo petroquímico, já que a mesma demanda uma mãode-obra altamente especializada. A maioria dos migrantes é oriunda de atividades anteriores no meio rural, e quando consegue ser absorvida, o é pelo setor terciário ou mesmo em subempregos, trajetória que vem sendo observada de longa data (BARBOSA, 1990 e 2002).

Para se ter uma idéia numérica recente dessa realidade, em 1999 o número de trabalhadores que possuíam carteira assinada em Paulínia era de 16.827. Dentre os subsetores da economia que mais empregavam, a indústria de transformação estava em destaque, respondendo por cerca de 30\% (5.573), dos trabalhadores ocupados. Na administração pública, as mulheres ocupavam maior participação, representando $45 \%$ das mulheres ocupadas no setor formal, respondendo por cerca de $70 \%$ dos trabalhadores na administração pública, com 2.255 mulheres empregadas.

Vale ressaltar que, de acordo com dados do IBGE, em 2001 a indústria foi o setor da atividade econômica que mais refletiu as deficiências do mercado de trabalho brasileiro nos últimos dez anos. A participação do setor como fonte de trabalho para as pessoas ocupadas caiu para $27,8 \%$, no período de 1991 a 2001. Quanto ao nível de emprego, na indústria paulista ocorreu redução de 
$2,02 \%$ no mesmo ano, reduzindo em 32,4 mil a quantidade de postos de trabalho. O número de empregos industriais chegou a 1,58 milhão em 2001, o pior desempenho desde 1994, de acordo com dados da Federação das Indústrias do Estado de São Paulo (FIESP). O emprego com carteira assinada também teve no setor industrial um forte recuo. Historicamente o setor com maior índice de trabalho formal, a indústria reduziu esse índice de 79,49\% das pessoas que nela trabalhavam em 1991, para 66,50\% na média de janeiro a novembro de 2001 , uma queda de $16,3 \%$. Essa realidade tem forte impacto para um município eminentemente industrial.

O impacto da transformação de um município, anteriormente distrito de Campinas, em pólo petroquímico, já se faz sentir há três décadas. Em outra pesquisa (BARBOSA, 1990) percebeu-se, a partir de entrevistas realizadas com os moradores - em sua maioria migrantes provenientes de diversos estados brasileiros, com experiência prévia no trabalho agrícola, atraídos pela promessa de emprego formal no setor industrial, mas que não conseguiram ser absorvidos por não possuírem qualificação profissional para esse tipo de atividade - na maior parte das vezes, quando conseguiram empregos, foi no setor terciário ou informal.

Pode-se observar naquelas entrevistas que $47,1 \%$ eram procedentes do meio rural, antes de se mudarem para Paulínia; 35,3\% dos entrevistados sempre viveram na cidade e somente $17,6 \%$ eram provenientes da zona urbana. Mesmos estes vieram de cidades de pequeno porte do interior paulista ou de Minas Gerais, e em sua maioria não tiveram passagens por cidades como São Paulo. Esses dados são próximos ao que se observa hoje, como já apontado.

Observando a história de vida dessas pessoas, percebe-se que os depoimentos se repetiam entre os procedentes da zona rural em relação à história da migração. A maior parte trabalhava em terras próprias - pequenos produtores - ou em terras familiares; outros eram empregados de grandes lavouras de laranja ou algodão. Em seus depoimentos, enfatizaram que "não dava mais para continuar trabalhando na terra, pois era duro". O trabalho nas terras que ocupavam anteriormente arregimentava toda a família, significando com isso que "trabalhavam que nem loucos e não conseguiam nada, só ter esperança de que no outro ano as coisas iam ser diferentes, mas era todo ano a mesma coisa: só ter esperança" (depoimento à autora).

A mudança para Paulínia significou a possibilidade de "largar os serviços na lavoura e tentar a sorte aquil". Muitos, em função de o serviço ser tão pesado 
e despender tantas energias de toda a família, "acreditavam que iam acabar morrendo de tanto trabalhar". Assim, tiveram a idéia de vender a terra, despedirse do emprego e mudar para tentar a vida de outra forma. $\mathrm{O}$ caminho não difere muito do traçado por diversos migrantes no Brasil e Paulínia acabou se concretizando como opção, porque muitos deles tinham amigos ou parentes que haviam feito a mesma trajetória e escreviam dizendo que lá havia possibilidades de emprego e de vida melhor. É bom destacar que esse tipo de convencimento é muito comum entre os migrantes mais antigos; nos mais recentes encontrou-se um outro tipo de discurso. Mas essencialmente nos moradores de Paulínia, já se percebia naquele momento um discurso voltado para "a vida na roça é difícil", e porque se "almeja melhorar de vida" (BARBOSA, 1990), até porque a presença da Petrobras no município, no início da construção da REPLAN (Refinaria de Planalto), exercia fascínio enorme nos migrantes.

O conteúdo da frase "melhorar de vida" tem um aspecto comum, entre os moradores entrevistados naquela época, tanto para os que tiveram de certa forma uma ascensão social, quanto para os desempregados. Paras os primeiros, isso significou deixar de trabalhar duro, conseguir uma casa própria, por exemplo, embora ainda estejam inseridos num trabalho pouco qualificado e remunerados. No entanto, seus filhos já conseguiram passar, através de concurso público, para os quadros das grandes indústrias, comprar um carro e ainda acumular alguns bens (terrenos, casas de aluguel, etc.). Os segundos, embora não tenham conseguido arranjar nem mesmo um trabalho pouco qualificado, ao menos compraram uma casa pelo Sistema Financeiro de Habitação e contam com a ajuda de filhos maiores e empregados para pagar a prestação. Ademais, têm podido oferecer à família as condições gerais mínimas de infra-estrutura básica: o acesso à saúde e à educação básica é um bom exemplo.

Resgatando as entrevistas realizadas com diversos moradores, em relação às atividades ocupacionais anteriores à vinda para o município, dentre os moradores observados, 52,9\% desenvolviam atividades na lavoura; $8,8 \%$ trabalhavam em serviços gerais (categoria que englobava, na pesquisa, os trabalhadores mais desqualificados e menos remunerados - faxineiros, braçais, cozinheiros, auxiliares em geral, etc.); $2,9 \%$ eram domésticas sem registro; $11,76 \%$ trabalhavam no lar e $9 \%$ em firmas empreiteiras. Somente $8,8 \%$ provinham do setor industrial e $11,7 \%$ de serviços municipais especializados. Atualmente, excetuando-se as atividades do lar, que são as de maior percentual entre os entrevistados $(35,3 \%)$ e os aposentados rurais $(17,6 \%)$, predominam 
os serviços gerais, já definidos (14,7\%); os servidores municipais especializados, nível técnico $(11,7 \%)$ e os desempregados $(11,7 \%)$. Somente $5,8 \%$ dos entrevistados trabalham em indústrias e 2,9\% em firmas empreiteiras. Em relação à ascensão profissional, fica evidente que a maioria não conseguiu se inserir no setor industrial, inclusive porque esse tipo de atividade requer um trabalhador mais especializado.

A inserção do trabalhador no setor industrial está limitada a duas exigências básicas. Em primeiro lugar, a de uma qualificação que corresponde às necessidades específicas daquele setor. Em segundo, esse requisito se desdobra na exigência de uma capacidade de desenvolver determinadas técnicas para a execução de tarefas específicas, o que pressupõe, por sua vez, novas normas de relações sociais e valores culturais tendentes à mobilização e motivação do trabalhador para a execução de determinadas tarefas (BARBOSA, 1990).

Já que o mesmo pólo petroquímico que abriga os moradores, esse quadro de dificuldades expõe as dificuldades de inserção dos mesmos ao trabalho industrial, projeto que inicialmente motivou sua mudança. Também traz embutidas outras questões, como a degradação do meio urbano, dos recursos hídricos e atmosféricos. Apesar dessas dificuldades, a visão que possuem da cidade pode ser considerada mais positiva que negativa. Identificam seus problemas de forma individual, não conseguem organizar-se politicamente para enfrentá-los, mas expressam suas dificuldades de outra maneira.

\section{$O$ sofrimento psíquico e os trabalhadores}

Paulínia não se constituiu como município industrial que foi sofrendo transformações de forma gradativa, mas um espaço onde foi oferecido suporte geofísico para alocar indústrias de grande porte, um complexo industrial no qual se organizou um parque industrial diversificado ao redor de uma comunidade existente e em expansão. Esse processo vem desencadeando problemas complexos na qualidade socioambiental do município e de sua população, desde sua instauração, nos anos 1970. Várias são as maneiras através das quais se pode observar sua complexidade; no entanto, a privilegiada nesta pesquisa é o sofrimento psíquico apresentado por uma parcela significativa de seus moradores, especificamente a depressão.

Para tanto, as condições objetivas para se analisar esse aspecto deverão considerar a especificidade do atendimento à saúde no município. Nesse sentido, 
vale ressaltar que simultaneamente à instalação da Refinaria de Planalto (REPLAN), iniciou-se a instalação de um programa de saúde específico para essa comunidade, vinculado à Faculdade de Ciências Médicas da Unicamp, que procurava renovar a prática médica enquanto proposta de ampliar a participação da população envolvida. Esse processo se iniciou também nos anos 1970, fruto de um convênio entre o governo do estado e a prefeitura do município, ocasionando então a constituição do Programa de Saúde Comunitária de Paulínia, através da construção do Centro de Saúde Escola. Este permitiria a realização de estágios, residência médica e mesmo desenvolvimento de atividades relacionadas à pós-graduação para os alunos da Faculdade de Ciências Médicas da Unicamp. ${ }^{12} \mathrm{O}$ programa se mostrou ímpar por suas características específicas e a qualidade do serviço oferecido. Atualmente o serviço de saúde não está mais vinculado à Universidade Estadual de Campinas, já que o convênio foi cancelado pela prefeitura municipal no final dos anos 1990.

A qualidade do serviço oferecido à comunidade permitiu constituir as unidades básicas de saúde como locais privilegiados, tornando-se espaços importantes para as idas constantes dos moradores às diferentes especialidades, principalmente para a área de Saúde Mental (uma das áreas que apresenta maior demanda em qualquer serviço público do país). Embora sejam locais importantes na questão básica que envolve pacientes e profissionais de saúde, é possível afirmar que o paciente não procura o serviço exclusivamente por estar com a saúde debilitada, ou porque carece de procedimentos eminentemente médicos.

Na realidade, a procura ao serviço de saúde ocorre de forma equivocada, porque legitimamente esse local tem sido espaço de acolhimento de todas as mazelas, dores (não exclusivamente físicas) e impotência da população frente a sua realidade social. Nesse sentido a área de Saúde Mental é o fim da linha dessa busca desordenada por procedimentos medicamentosos. ${ }^{13}$ Mas não qualquer fim de linha, já que se encaixa de forma perfeita a esse desejo inconsciente e mal-ordenado, já que sua própria natureza é altamente medicamentosa, tanto em procedimentos psicofármacos, quanto em espaços terapêuticos, como oficinas e grupos, podendo propiciar vinculação e atenção às queixas dos pacientes de forma integral. A partir de entrevistas realizadas com profissionais de saúde (médicos, sanitaristas e psiquiatras que atendem nos serviços do município), em diferentes momentos ao longo da pesquisa, podem-se constatar alguns aspectos importantes, como os depoimentos a seguir procuram evidenciar: 
O médico é exigido para tapar todos os buracos, que não só da relação médico-paciente (depoimento à autora).

[...] a gente fica com pessoas que procuram o serviço de saúde duas, três, quatro vezes por mês com aquela mesma queixa: "uma bola que sobe e desce do estomago, e me dá uma coisa ruim", ou então cada dia vem com uma coisa diferente (depoimento à autora).

A partir desses depoimentos se evidenciou a busca desordenada dos usuários (pacientes) pelo serviço de forma exacerbada, principalmente na área de Clínica Médica. Mostra-se desta forma uma população carente de procedimentos médicos, que se tornou por fim altamente medicalizada. A reflexão desta pesquisa incide na hipótese de que essa busca é uma metáfora, pois não se restringe à questão da saúde, mas tenta encobrir algo que não se tem onde pedir ou buscar.

[...] cada dia vem com uma coisa: coceira na ponta do cabelo, dor embaixo da unha, outro dia é "uma coisa ruim, doutor, que eu não sei explicar direito". Aí eu digo: "Minha senhora, se a senhora não me explicar como é, eu não posso adivinhar". "Ah! Mas o senhor sabe, o senhor é médico [...]”. É claro que do ponto de vista psicossocial a gente ocupa esse espaço [mas] é muito perigoso. Eu acho que a medicina é uma coisa técnica: você sabe, você tem um conhecimento [...], mesmo o fato de eu entender que a doença dela tem origem no social, nas relações sociais, isso é uma coisa técnica, eu aprendi isso, é desse ponto de vista que eu digo técnico (depoimento à autora).

O depoimento demonstra muito claramente que, embora reconhecendo a dificuldade de lidar com essa exacerbação de sintomas (tanto o paciente quanto o médico demonstram no diálogo narrado essa dificuldade), fica claro que não se pode fugir de um debate mais amplo sobre o significado dos mesmos, e a exigência é feita para um caráter mágico e de autoridade que a figura do médico impõe. Negar esse aspecto é negar a complexidade de seus significados.

Por fim, é importante ressaltar um ponto importante e que tem a ver com a dinâmica da própria essência das atividades profissionais desenvolvidas, tanto por pescadores artesanais, quanto por trabalhadores da indústria. Em entrevista, a coordenadora do Centro de Apoio Psicossocial de Paulínia, ao conversar sobre a diferenciação de gênero entre os pacientes que freqüentam o serviço, apontou que as mulheres perdem pouco o vínculo com o trabalho, 
considerando pacientes com crises depressivas e outros tipos de sofrimento psíquico. No entanto, os pacientes homens têm o discurso de que adoeceram no trabalho, e nesse sentido têm muitas dificuldades para se inserir em oficinas terapêuticas, relatando inclusive episódios de medo e pânico frente a essa solicitação. A proposta de desenvolver oficinas terapêuticas poderia tornar-se uma fonte alternativa de renda, já que grande parcela dos mesmos se encontra afastada do trabalho, recebendo pensão do INSS devido à incapacidade, mas isso se torna muito difícil e tende a piorar o estado psíquico dos mesmos.

Esse dado é bastante significativo no conjunto da complexidade observada tanto no material encontrado em relação aos pescadores artesanais quanto aos trabalhadores industriais, o que em muito corrobora a perspectiva elaborada por outros autores, como Dejours, que em texto de 1987, analisando a doença somática e a organização do trabalho, chama atenção para um aspecto importante:

as doenças somáticas aparecem sobretudo em indivíduos que apresentam uma estrutura mental caracterizada pela pobreza ou ineficácia das defesas mentais [...]. Quando as defesas características e comportamentais não conseguem conter a gravidade dos conflitos ou a realidade, tais sujeitos não descompensam de um modo neurótico, nem de um modo psicótico (DEJOURS, 1987, p. 126).

A desorganização à qual sucumbe o doente não se traduz necessariamente por sintomas mentais, mas pelo aparecimento de uma doença somática, fato bastante significativo no contexto do município de Paulínia.

A partir da constatação desse autor e pelo material analisado, fica evidente que o medo em relação ao trabalho como desencadeador de sofrimento psíquico carece de consideração especial. Fica evidente também outro aspecto, que é a camuflagem do medo no ambiente de trabalho, que, como tão bem atestou Dejours (1987) em suas pesquisas com operários da construção civil e da aviação de caça, faz parte de um acordo tácito que comprova a virilidade. Não é permitido assumir o medo, pois este poderia comprometer os sinais exteriores de virilidade e bravura frente à comunidade (DEJOURS, 1987, p. 69).

Vários aspectos podem ser observados a partir da pesquisa de campo e dos depoimentos dos entrevistados. No entanto, a preocupação fundamental em relação à depressão no contexto contemporâneo tem permitido relacionar os depoimentos com outra abordagem sobre a depressão que foge do seu aspecto 
eminentemente psiquiátrico e, conseqüentemente, diagnóstico, estando diretamente vinculado ao discurso da ciência moderna.

Assim, a observação tanto do discurso da ciência e sua materialização - os diagnósticos psiquiátricos - e a presença da depressão nos grupos sociais analisados permitiram reconhecer uma padronização e homogeneização de todas as manifestações sociais, inclusive dos diferentes tipos de sofrimento psíquico depressão, busca de uma identidade social, impotência do indivíduo frente às transformações socioambientais de seu cotidiano -, buscando desta forma inserilos em protocolos médicos e nas possibilidades medicamentosas, como a única forma de encontrar uma saída para o sofrimento social.

Desta forma, duas categorias devem ser consideradas para se entender a dinâmica do discurso da ciência, pois são de fundamental importância para a constituição de um outro olhar sobre a depressão: diagnóstico e sintoma. Aspectos aparentemente interligados, mas que para serem de fato compreendidos devem ser analisados procurando-se superar o caráter de sinônimos com que são tratados pelo discurso da ciência, sobretudo porque se reconhece nesta pesquisa que o diagnóstico está vinculado à psiquiatria e o sintoma está singularizado à psicanálise - assim, não podem ser encarados como sinônimos.

A partir dessa consideração, duas facetas interligadas devem ser abordadas. A primeira diz respeito à depressão e sua forte incidência na contemporaneidade, enquanto expressão patogênica da saúde mental: o que ela está querendo representar? Por que há hoje um expressivo quadro que aponta para os inúmeros diagnósticos de depressão no meio social e, conseqüentemente, tanto investimento científico e de recursos materiais e humanos para se entender essa morbidade, extrapolando de forma significativa as fronteiras do conhecimento psiquiátrico e procurando inseri-la para além do seu referencial (a psiquiatria)? Outro aspecto a ser mencionado diz respeito à consideração que deve ser levada em conta, com relação ao avanço na elaboração dos diagnósticos dos estados depressivos e do sofrimento psíquico em geral na sociedade. Em decorrência disso, muitas das formas de sofrimentos psíquicos estão sendo diagnosticadas e medicalizadas como depressão, permitindo que se possa afirmar que no século atual a depressão assumiu caráter importante, muito provavelmente em função da sofisticação dessas possibilidades diagnósticas. Mas, como afirma Bolguese (2003), a consolidação da depressão como categoria da nosografia psiquiátrica evidencia uma tomada de posição relacionada a uma origem ideológica. A autora vai mais fundo, ao afirmar: "Hoje, 
tudo é depressão. E se tudo é depressão, a depressão não é nada" (BOLGUESE, 2003, p. 191).

O sintoma, por outro lado, possui outra dimensão e abordagem. Apesar da multiplicidade de pacientes depressivos, não se pode perder a orientação psicanalítica que ensina que a singularidade do sintoma, em cada indivíduo, o tornará particular, tanto o sujeito quanto seu sintoma. É nesse sentido que o sintoma tem algo de real, pois nenhum outro é igual, tornando-se desta forma rebelde, inquieto e significativo (GALVÃO, 2002).

Mas, se o sintoma é o fundamental e se a depressão está aqui sendo considerada sintoma, expressão da subjetividade dos indivíduos, construção da ciência e da cultura, existe de forma subjacente um outro desafio: qual deve se dar na maneira mais adequada para enfrentar os inúmeros diagnósticos de depressão em nosso meio social?

Com a psiquiatria, aprende-se que a depressão não é considerada apenas um sintoma, mas uma morbidade, e que em função disso precisa ser tratada e curada. Para tal deve ser colocado à disposição do paciente todo o arsenal medicamentoso de última geração, já que todo o investimento da ciência médica e psicofarmacológica nos últimos anos tem permitido um avanço significativo para entender a nosografia própria da depressão e as melhores condutas para tal fim. No entanto, o que se tem observado é que, apesar de todo esse investimento, a depressão tem aumentado e se multiplicado enquanto expressão sintomática, e muitos pacientes não respondem de forma concreta exclusivamente aos tratamentos medicamentosos - nas entrevistas com os pescadores artesanais esse aspecto ficou evidente.

Assim, com a psicanálise a depressão pode ser entendida enquanto um sintoma. Sintoma no sentido do que nos aponta Kaufmann (1996) e nos reforça Galvão (2002): "no princípio era o sintoma" (GALVÃO, 2002, p. 81), e foi com o sintoma que Freud teve que se haver e deixar um incômodo legado: a própria psicanálise. O sintoma que despertou em Freud seu interesse, sua curiosidade e sua sabedoria para descortinar o inconsciente não foi qualquer sintoma, mas, como se sabe, o sintoma histérico, que permitiu a Freud, ao deixar-se ouvir pela histeria, encontrar um sujeito que estava em pane ou incapaz de se expressar. Como alerta Kaufmann (1996, p. 478), Freud se viu assim diante do "enigma moderno por excelência, o do limite do poder da fala e portanto da captação de si mesmo e do objeto". 
A partir dessa constatação e pensando na construção da subjetividade e identidade na complexidade social de nosso tempo, pode ser muito mais cômodo e plausível identificar-se a partir de um diagnóstico do que entrar em contato com a constituição de um sintoma. Identificar-se com a depressão, identificarse com a síndrome do pânico - aliás, diagnósticos bastante contemporâneos do que buscar entender o significado de um sintoma, e, com isso, tentar reelaborálo e ressignificá-lo. A experiência empírica proveniente das pesquisas realizadas, longe de constituir-se na experiência clínica da psicanálise, tem permitido observar essa identificação entre os sujeitos pesquisados, com seus diagnósticos:

Sou deprimido... (pescador 01, depoimento à autora).

O meu problema é depressão... (pescador 02, depoimento à autora).

Eu tenho síndrome do pânico, e já pesquisei tudo na Internet sobre isso. (pescador 03, depoimento à autora).

Desta forma, acredita-se que o excesso de diagnósticos de depressão, a necessidade exacerbada por medicamentos e a identificação, no sentido da construção da identidade, do sujeito com o diagnóstico, devem possuir estreito vínculo. No fundo, ao se tratar desses temas e da prevalência dos diagnósticos homogêneos de depressão na atualidade, um retorno a Weber é imprescindível, pois com sua análise sobre a modernidade já nos tinha alertado para o precioso conceito de desencantamento do mundo. Este, como nos ensina passo a passo Pierucci (2003), possui dois significados em sua obra: a) desencantamento do mundo pela religião e b) desencantamento do mundo pela ciência. Ambos aspectos dizem respeito ao momento vivido e a suas transformações mais elementares. Pensar o homem contemporâneo desencantado poderia induzir a pensar que a depressão pode ser considerada uma das expressões da tragédia da cultura humana (transformações globais e planetárias, guerras, violência, escassez dos recursos naturais, degradação socioambiental, desemprego, péssimas condições de moradia e de relacionamentos)? O sujeito contemporâneo na modernidade, não tendo a que ou a quem recorrer (nem religião e nem ciência), expressaria seu sofrimento, seu desencantamento através de depressão, e conseqüentemente empreenderia uma busca constante por paliativos (medicamentos), para calar seu desejo ou sua dor?

Assim, acredita-se que essas reflexões tenham provocado muito mais perguntas do que oferecido respostas. Contudo, a experiência empírica e o 
contato intenso com os entrevistados foi o fator desencadeante para continuar a investir nesta abordagem e na possibilidade concreta do reconhecimento de um íntimo relacionamento entre os problemas socioambientais e a depressão, enquanto um forte sintoma social.

\section{Algumas considerações finais}

Ao finalizar, vale ressaltar alguns pontos importantes que a pesquisa sobre a depressão e a complexidade social propiciou. Primeiro, reconhecer a exigência do próprio objeto, da incorporação de uma abordagem interdisciplinar, pois é impossível para a pesquisadora, frente a essa temática, fechar-se num monólogo disciplinar. No entanto, a referência conceitual inicial interdisciplinaridade - tem sido em muito ultrapassada, como se procurou apontar ao longo do texto, através da incorporação de outra proposta conceitual - multireferencialidade -, aliadas ao reconhecimento da significativa questão social e suas transformações socioambientais, como fundamentais para se entender o sujeito contemporâneo, sem abrir mão, no entanto, de considerar a subjetividade.

Em decorrência, um segundo ponto indica a constatação de que a subjetividade, na contemporaneidade, tem-se alterado, tornando-se necessário rever esse conceito ou talvez reconceituá-lo. Isso pode ser evidenciado através da expectativa que se constrói sobre os tratamentos psicoterápicos, muitos dos quais, independentemente de suas abordagens, têm trabalhado com sucesso na esfera da realidade psíquica, mas não têm sido capazes de rever a noção da própria subjetividade. Às queixas dos pacientes têm-se ajuntado os problemas que não são mais meramente subjetivos no sentido antigo, mas que, com significativo aumento da consciência subjetiva, ficam confrontados com uma realidade que desintegra o mundo onde todas as subjetividades deveriam estar sustentadas.

Outro ponto importante diz respeito ao aprofundamento do diálogo com os acometidos (aqueles com diagnóstico de depressão), porque é através do discurso desses sujeitos que se espera avançar no entendimento da abordagem teórica da complexidade social. Embora considerando a importância dos diagnósticos formulados pelos profissionais de saúde mental sobre esses trabalhadores, deve-se procurar ultrapassá-los através da ausculta dos discursos dos envolvidos e investir na análise dos depoimentos dos indivíduos residentes nessas comunidades, já que os mesmos tentam de alguma forma romper com 
uma situação dada e esperada, mesmo que provisoriamente construída a partir da identidade com o diagnóstico.

A identificação dos problemas ambientais dessas comunidades permitiu uma série de considerações a respeito da possível associação entre sofrimento psíquico e transformações socioambientais. Assim, abordagens diferenciadas, ultrapassagem de referências disciplinares, como se propõe, e a consideração da depressão como importante sintoma social, que evidencia a complexidade do momento presente, permitirão rediscutir a compreensão do próprio sentido da qualidade de vida, considerando que para se conquistar a melhora da qualidade de vida será fundamental e interdependente observar as diferentes linguagens que dão conta das qualidades da vida (HILLMAN, 1993, p. 12).

\section{Referências}

BARBOSA, Joaquim Gonçalves (Org.). Multi-referencialidade nas Ciências e na Educação. São Carlos: EDUFSCar, 1998.

BARBOSA, Sônia R. C. S. Ambiente, subjetividade e complexidade: um estudo sobre depressão no litoral norte paulista. Projeto Individual FAPESP (processo n. 04/10685-1), 2005, em andamento.

. Ambiente, subjetividade e complexidade: um estudo sobre depressão no litoral norte paulista. Relatório parcial, FAPESP(processo n. 04/10685-1), 2006.

Contribuições a um olhar diferenciado sobre sociedades complexas: a qualidade de vida e as transformações socio-ambientais nos pólos petroquímicos de Duque de Caxias, RJ e Paulínia, SP. Relatório técnico, FAEP n. 01081/2001, 2002.

. Dores sentidas, dores vividas. Cadernos do ICH - PUCCampinas, Campinas, n. 9, 1999.

. Industrialização, ambiente e condições de vida em Paulínia(SP): as representações de ambiente e saúde para médicos e pacientes. Dissertação (Mestrado em Sociologia) - Instituto de Filosofia e Ciências Humanas, Universidade Estadual de Campinas, Campinas, 1990.

Qualidade de vida e suas metáforas: uma reflexão socioambiental. Tese (Doutorado em Ciências Sociais) - Instituto de Filosofia e Ciências Humanas, Universidade Estadual de Campinas, Campinas,1996. 
Qualidade de vida em Itaipu, Niterói, Rio de Janeiro. Relatório de atividades. In: BEGOSSI, Alpina (Org.). Pesqueiros e territórios na pesca artesanal. Parte II: áreas costeiras do Rio de Janeiro e da Bahia. Relatório parcial de pesquisa, FAPESP, n. 01/00718-1, 2002a.

- Qualidade de vida em Itaipu, Niterói, Rio de Janeiro. Relatório de atividades. In: BEGOSSI, Alpina (Org.). Pesqueiros e territórios na pesca artesanal. Parte II: áreas costeiras do Rio de Janeiro e da Bahia. Relatório parcial de pesquisa, FAPESP, n. 01/00718-1, 2003

- Qualidade de vida em sociedades complexas: a depressão entre trabalhadores da indústria petroquímica e pescadores artesanais. Projeto Individual FAPESP (processo n. 03/00175-3), 2003 a.

- Qualidade de vida em sociedades complexas: a depressão entre trabalhadores da indústria petroquímica e pescadores artesanais. Relatório final, FAPESP (processo n. 03/00175-3), 2005 a.

BARBOSA, Sônia R. C. S.; BEGOSSI, Alpina. Fisheries, Gender and Local Changes in Itaipu Beach, Rio de Janeiro, Brazil: an individual approach. Revista Multiciência. Disponível em www.multiciencia. unicamp.br. Acesso em maio 2004.

BEGOSSI, Alpina. Ecologia de Pescadores da Mata Atlântica e da Amazônia. São Paulo: HUCITEC/NEPAM-UNICAMP/NUPAUB-USP/ FAPESP, 2004.

Pesqueiros e territórios na pesca artesanal. Parte II: áreas costeiras do Rio de Janeiro e da Bahia. Relatório final de pesquisa, FAPESP (processo n. 01/00718-1), 2003.

BOULGUESE, Maria Sílvia. Depressão e doença nervosa moderna. In: FUKS, Lúcia Barbero; FERREIRA, Flávia Carvalho (Orgs.). Desafios para a psicanálise contemporânea. São Paulo: Escuta, 2003. p.191-201.

COSTA PEREIRA, Mário Eduardo. A paixão nos tempos do DSM: sobre o recorte operacional do campo da Psicopalogia. Lês Etats Généraux de la Psychanalyses -@rchives-2001 \{http://www.etatsgeneraux-psychanalyse.net/ archives/texte88.html), 10 de junho de 2004.

DEJOURS, Christophe. A loucura do trabalho: estudo de psicopatologia do trabalho. São Paulo: Cortez, 1987. 
DELOUYA, Daniel. Depressão. São Paulo: Casa do Psicólogo, 2001.

DIAS, Mauro Mendes. A posição do sujeito na depressão: uma abordagem psicanalítica.: Caderno do Seminário: Neuroses e Depressão. Lições I a IV. Campinas: Instituto de Psquiatria de Campinas, 2003.

DOMINGUES, José Maurício. Sociologia e modernidade. Para entender a sociedade contemporânea. Rio de Janeiro: Civilização Brasileira, 2001.

DUARTE, Luiz Fernando Dias. As redes do suor: a reprodução social dos trabalhadores da pesca em Jurujuba. Niterói: EDUFF, 1999.

FÉDIDA, Pierre. Depressão. São Paulo: Escuta, 1999.

Escuta, 2002.

Dos benefícios da depressão: elogio da psicoterapia. São Paulo:

FERREIRA, Lucia da Costa .Traditional population, property rigths and sustainability in the Ribeira Valley, SP In: ANAIS of the 2000 Annual Meeting of The Society for Applied Antropology, San Francisco, California, 2000.

FERREIRA, Lucia da Costa; CAMPOS, Simone Vieira. Contemporary Social Conflicts: the Relationships between Brazilian Environmentalists, Governments and Traditional People. In: WORLD CONGRESS OF RURAL SOCIOLOGY, 10. Annals, Rio de Janeiro, 2000.

FREUD, Sigmund. Luto e melancolia. In: Artigos sobre metapsicologia. Rio de Janeiro: Imago, 1999.

O mal-estar da civilização. Rio de Janeiro: Imago, 1997.

GALVÃO, Manoel Dias. O sintoma na psicanálise e na psiquiatria. In: VIOLANTE, Maria Lúcia V. (Org.). O (im)possível diálogo psicanálise e psiquiatria. São Paulo: Via Lettera, 2002. p. 81-100.

GIDDENS, Anthony. As conseqüências modernidade. São Paulo: Unesp, 1991.

HALL, Stuart. A identidade cultural na pós-modernidade. $4^{\mathrm{a}}$ ed. Rio de Janeiro: DP\&A, 2000.

HILlMAN, James. Cidade \& alma. São Paulo: Studio Nobel, 1993.

KAUFMANN, Pierre (Ed.). Dicionário Enciclopédico de Psicanálise. O legado de Freud e Lacan. Rio de Janeiro: Jorge Zahar, 1996. 
KLEINMAN, Arthur (Ed.). Culture and depression. Studies in the Anthropology and Cross-cultural Psychiatry of Affect and Disorder. California: University of California Press, 1985.

KRISTEVA, Julia. As novas doenças da alma. Rio de Janeiro: Rocco, 2002. LACAN, Jacques. Escritos. Rio de Janeiro: Jorge Zahar, 1998.

LIMA, Roberto K. de. Pescadores de Itaipu: meio ambiente, conflito e ritual no litoral do Estado do Rio de Janeiro. Niterói: EdUFF, 1997.

LIPOWISK, Z. Somatization: the Concept, its Clinical Application. Am J Psychiatry, n. p. 145, November 1988.

ORGANIZAÇÃO MUNDIAL DA SAÚDE (Coord). Classificação de Transtornos Mentais e de Comportamento da CID-10: descrições clínicas e diretrizes diagnósticas. Porto Alegre: Artes Médicas, 1993.

PESSANHA, Elina G. F. Os companheiros: trabalho e sociabilidade na pesca de Itaipu. Niterói: EdUFF, 2003.

PIERUCCI, Antonio Flavio. O desencantamento do mundo: todos os passos do conceito em Max Weber. São Paulo: Ed. 34, 2003.

ROUDINESCO, Elisabeth. Por que a psicanálise? Rio de Janeiro: Zahar, 2000.

SOLOMON, Andrew. O demônio do meio dia: uma anatomia da depressão. Rio de Janeiro: Objetiva, 2002.

WEBER, Max. A ética protestante e o espírito do capitalismo. São Paulo: Companhia das Letras, 2004.

WINNICOTT, Donald. Tudo começa em casa. $3^{\text {a }}$ ed. São Paulo: Martins Fontes, 1999.

WOLPERT, Lewis. Tristeza maligna: a anatomia da depressão. São Paulo: Martins Fontes, 2003. 


\section{NOTAS}

- Doutora em Ciências Sociais pela UNICAMP; pesquisadora do Núcleo de Estudos e Pesquisas Ambientais (NEPAM / UNICAMP). Endereço eletrônico: srcal@unicamp.br.

${ }^{1}$ A pesquisa que origina este artigo foi realizada com recursos financeiros da Fundação de Amparo à Pesquisa do Estado de São Paulo (FAPESP), processo n. 03/00175-3, pelo qual agradecemos.

${ }^{2}$ Essa expressão foi construída pela autora, tendo como referência leituras antropológicas e psicanalíticas. Exclusivamente em Lipowisk (1988) foi encontrada expressão semelhante.

${ }^{3} \mathrm{O}$ termo é amplamente usado nos programas de saúde pública e está centrado na idéia da universalidade e humanização dos serviços de saúde. Ver: <http://portalweb02.saude.gov.br/ saude/buscar.cfm>, 29 jan. 2004. Na área de Saúde Mental, no nosso entender, esse termo pode gerar um sentimento de passividade frente à relação médico-paciente e criar uma expectativa falsa em relação ao profissional ou mesmo ao serviço.

${ }^{4}$ Vale destacar: sobre Itaipu: Lima (1997), Pessanha (2003), Barbosa (2003; 2003a, 2005), Begossi (2003, 2004), Barbosa e Begossi (2004). Sobre Paulínia: Barbosa (1990, 2002).

${ }^{5}$ Existe uma vastidão de diagnósticos nesta área, que se tem transformado ao longo do tempo. As diferentes abordagens diagnósticas realizadas pelos psiquiatras, que são os profissionais que detêm ferramentas e poder do diagnóstico, são orientadas e sistematizadas pelo manual da Associação Mundial de Psiquiatria - DSM IV -, em vigor nesta versão desde 1994, e que fornece subsídios empíricos e teóricos para a Classificação de Transtornos Mentais e de Comportamento da CID-10: Descrições Clínicas e Diretrizes Diagnósticas, da Organização Mundial da Saúde. Os psicólogos que atuam nos serviços públicos de saúde, especialmente os CAPS, também referendam esses diagnósticos e se pautam pela DSM IV, inclusa no capítulo de transtornos mentais da CID-10. Para uma crítica substantiva sobre a utilização do DSM IV, reportamos o leitor a Costa Pereira (2001). Vale ainda ressaltar que os psicanalistas, mesmo os de formação psiquiátrica, evitam diagnosticar um paciente, já que sua referência está centrada no sujeito que sofre e, conseqüentemente, no discurso do sujeito que sofre. Desta forma, a aproximação desses conceitos ou diagnósticos com a subjetividade nos remete à incursão nesta abordagem e, assim, no discurso da psicanálise.

${ }^{6}$ Essa afirmação é baseada no conflito paradigmático que se nota, e que resulta nas abordagens diferenciadas entre psiquiatras de formação exclusivamente clínica e outras vertentes como a psicanálise, a homeopatia, a medicina chinesa, dentre algumas das mais significativas. 
${ }^{7}$ Entrevista concedida pelo presidente da colônia a Alpina Begossi, em janeiro de 2002.

${ }^{8}$ Observação oriunda das entrevistas à autora durante o trabalho de campo realizado, no período de janeiro e julho de 2003.

${ }^{9}$ Serão considerados portadores de depressão grave, nesta pesquisa, aqueles que já apresentaram surtos psicóticos, fazem acompanhamento medicamentoso e terapêutico, bem como precisaram afastar-se das atividades profissionais, como a pesca, por períodos mais ou menos longos.

${ }^{10}$ Entrevista prestada à autora pela psicóloga do Centro de Saúde de Engenho do Mato, em julho de 2002.

${ }^{11}$ Essa afirmação já foi constatada em pesquisa anterior (BARBOSA, 1990, 1996).

${ }^{12}$ Para mais detalhes, consultar Barbosa (1990).

${ }^{13}$ Em pesquisa anterior, tanto para o município de Paulínia como em outra realizada nos municípios de Campinas, Sumaré, Piracicaba e Bragança Paulista, esses aspectos foram observados e comprovados. Para tanto reportamos o leitor a Barbosa $(1990,1996)$. 


\section{ABSTRACT}

\section{Subjectivity and Social Complexity: Contributions to the Study of Depression}

This paper presents a reflection based on some results of the research project Quality of life in complex societies: the depression between workers of petrochemical industry and artisan fishermen. Is must be pointed out that this research is a large part of a deep theory developed since the 90's. In a deep field research, the quality of life through analysis of depressive states in workers of the petrochemical industry (REPLAN, Paulínia, SP) and artisan fishermen (7 Colony Z - Itaipu and Piratininga, Niterói, Rio de Janeiro) was examined, considering that these workers are under intense social-environmental transformations in their daily routine and revealing depression as expression of subjectivity, in the individual, of an intense social complexity.

Key words: Subjectivity; social complexity; depression; quality of life. 